\title{
POLYMER-FLR FOR MUD FLUID LOSS REDUCTION
}

\author{
Robert Dery Nagre ${ }^{1, *}$, Lin Zhao ${ }^{2}$, Isaac Kwesi Frimpong ${ }^{1}$
}

https://doi.org/10.23939/chcht12.01.079

\begin{abstract}
A fluid loss reducer polymer (polymer-FLR) was synthesized using acrylamide, hydroxyethyl methacrylate, $N$-vinyl pyrrolidone, and $N, N$-dimethyl acrylamide by free radical polymerization, followed by partial hydrolysis. Its composition was confirmed using FTIR and ${ }^{1} \mathrm{H}$ NMR spectroscopy. API mud fluid loss reduction of polymerFLR was about 10-fold lower than the blank. High temperature, high pressure fluid loss reduction of about 9-fold were achieved compared with the blank.
\end{abstract}

Keywords: synthesis, polymer-FLR, drilling mud, fluid loss, mud properties.

\section{Introduction}

The complexity of the problems encountered in petroleum well drilling necessitates the adjustment of recipes for formulation of appropriate fluids. The rheology of the drilling fluid is influenced by factors such as temperature, pressure, salinity, composition and the nature of the continuous fluid phase $[1,2]$. Temperatures increase as a result of the positive geothermal gradient and also because of frictional interaction between the drill bit and the formation during drilling operations. Hydrostatic pressure is a function of depth and increases with a drilling depth [3]. Different pollutants such as monovalent and divalent salts introduced into the mud during drilling can considerably affect the mud functional properties and should be taken into account while designing the drilling fluids by the addition of suitable additives which offer stability to its chemical composition [4].

Water-based muds are more desirable because of their low cost, abundance of the water as the primary fluid phase and their eco-friendliness. Technical challenges, particularly, fluid loss and poor rheological stability at high temperatures and under high salinity tend to limit their widespread applications. Breakdown of fluid loss control agents causes a large increase in the fluid loss accompanied

\footnotetext{
${ }^{1}$ Department of Chemical Engineering, Kumasi Technical University, P. O. Box 854, Kumasi, Ghana

${ }^{2}$ College of Petroleum Engineering, Yangtze University, 430100, Caidian, Wuhan, China

*nagrerobert@yahoo.com

(c) Nagre R., Zhao L., Frimpong I., 2018
}

by an increase in a filter cake thickness. This condition triggers excessive drag, high-pressure surges, differentialpressure sticking, and reduction in production-zone permeability as well as increases in shale sloughing [5-8].

Defects of the following two conventional polymers used in petroleum industry are challenges to deal with. Partially hydrolyzed polyacrylamide has been widely applied under ordinary conditions in the petroleum industry because of its attractive viscosity and cost-effectiveness, however, it has been unsuitable for high temperature, high salinity, and high flow rate injection conditions because of chain collapse, hydrolysis, decomposition, degradation and shear damage [9-11]. Xanthan biopolymer is not subjected to shear degradation, nor loss of viscosity in the presence of high salinity brines [10, 12]. However, it is prone to thermal instability and microbial degradation, besides its cost implication.

Polymers used as improved filtration-control agents should be water-soluble, thermally stable and resistant to alkaline hydrolysis and also remain effective in the presence of electrolytes [13, 14]. Copolymers which retain drilling fluids properties at elevated temperatures and high concentrations of dissolved electrolytes are viewed as antidote to the problems associated with the use of conventional polymers. Homopolymers do not afford the scope of attributes necessary for severe well environmental conditions. However, heteropolymerisation accords the capacity to combine the desirable properties of two or more different homopolymers into a single copolymer with attractive functionalities. This work discusses the characteristics of synthetic polymer-FLR earmarked for mud fluid loss reduction.

\section{Experimental}

\subsection{M aterials}

The materials used for the synthesis of polymer-FLR are stated as follows: acrylamide (AM, $98.0 \%$ purity); $\mathrm{N}$-vinyl pyrrolidone (NVP, 99.0\%); $\mathrm{N}, \mathrm{N}$-dimethyl acrylamide (DMAM, 98.0\%); hydroxyethyl methacrylate (HEMA, 96.0\%); 2-2'-azobisisobutyronitrile (AIBN, $94.5 \%)$; sodium hydroxide $(96.0 \%)$; acetone $(99.5 \%)$; ethanol (99.7\%); methanol (99.5\%), deionised water. 


\subsection{Synthesis of Polymer-FLR}

Polymer-FLR was synthesized in a three-neck flask equipped with a magnetic stirrer, nitrogen gas delivery tube and a thermostatic water bath by a free radical polymerization in deionized water under nitrogen sparging using 2-2'-azobisisobutyronitrile as an initiator. The polymerisation was performed using a monomer molar feed ratios of $46 \% \mathrm{AM} / 20 \% \mathrm{HEMA} / 26 \% \mathrm{NVP} / 8 \% \mathrm{DMAM}, 15.3 \mathrm{wt} / \mathrm{v} \%$ total monomer concentration, $\mathrm{pH}$ of 7.0 , at $333 \mathrm{~K}$ and the initiator dosage of $0.5 \mathrm{wt} \%$ for a reaction time of $1.0 \mathrm{~h}$. The acrylamide was first dissolved in deionised water and introduced into the flask under nitrogen degassing. The specified quantities of $N, N$-dimethyl acrylamide (DMAM), $N$-vinyl pyrrolidone (NVP), hydroxyethyl methacrylate (HEMA) and 2-2'-azobisisobutyronitrile (AIBN) were mixed and added to the flask whilst stirring and the temperature set to $338 \mathrm{~K}$. After a thick viscous mass was formed, the content was transferred into a beaker and allowed to cool. Specified amount of $0.2 \mathrm{~N}$ methanolic sodium hydroxide was added, stirred to uniformity and allowed to partially hydrolyse the acrylamide component of the polymer-FLR at $298 \mathrm{~K}$ for 4 days in a sealed beaker. The polymer was then isolated and purified using an excess acetone and finally dried at $333 \mathrm{~K}$.

\subsection{Polymer-FLR Property M easurements}

Presence of monomers and the structure of polymerFLR were confirmed by Fourier transform-infrared (FTIR) and proton nuclear magnetic resonance ( ${ }^{1} \mathrm{H} N M R$ ) spectroscopy, in accordance with some previous reports [9, 15-17]. FTIR spectra in the wave number range of 4000 $400 \mathrm{~cm}^{-1}$ were recorded on a Nicolet 370 FTIR spectrometer (USA) from powder-pressed $\mathrm{KBr}$ pellets with $\mathrm{D}_{2} \mathrm{O}$ as solvent and tetramethylsilane (TMS) as an internal reference. ${ }^{1} \mathrm{H}$ NMR spectra were recorded on a Bruker Ascend TM 600 NMR spectrometer at room temperature.

The thermogravimetric analysis (TGA) and differential thermal analysis (DTA) of freshly dried polymer-FLR were conducted using $4.96 \mathrm{mg}$ of the polymer under nitrogen atmosphere at a heating rate of $10 \mathrm{~K} / \mathrm{min}$ from 298 to $873 \mathrm{~K}$, using Perkin Elmer AscendTM 600 MHZ thermal analyzer.

\subsection{Assessment of Polymer-FLR Performance in Drilling Mud}

Mud samples were prepared and tested initially and after $16 \mathrm{~h}$ of hot-rolled aging according to American Petroleum Institute (API) procedure [18]. The salt contaminated mud was formulated using the ingredients, added in the order listed as follows: $500 \mathrm{~g}$ water $+25 \mathrm{~g}$ bentonite clay $+1.25 \mathrm{~g} \mathrm{NaOH}+7.5 \mathrm{~g}$ sulfonated lignite resin $(\mathrm{SPNH})+7.5 \mathrm{~g}$ sulfomethylated tannin $(\mathrm{SMT})+25 \mathrm{~g}$ $\mathrm{NaCl}+3.0 \mathrm{~g}$ polymer-FLR $+100 \mathrm{~g}$ barite.

Blank samples were prepared without the addition of polymer and tested under the same conditions. The apparent viscosities (AV), plastic viscosities (PV), and yield points (YP) of the mud samples were determined by recording viscometer readings at 600,300, 200, 100, 6 and $3 \mathrm{rev} / \mathrm{min}$ and computation using the following formulae:

$$
\begin{gathered}
A V=\frac{\emptyset_{600}}{2}, \mathrm{cP} \\
P V=\varnothing_{600}-\emptyset_{300}, \mathrm{~Pa} \\
Y P=\varnothing_{300}-P V, \mathrm{~kg} / \mathrm{m}^{2}
\end{gathered}
$$

Standard API filtrate loss was determined according to API procedure [18] using a standard filter area of $4581 \mathrm{~mm}^{2}$ and filtration pressure of $700 \mathrm{kPa}$. The cylinder was removed before the pressure was released. The volume of the filtrate was collected in $30 \mathrm{~min}$ as the fluid loss in cubic centimeters $\left(\mathrm{cm}^{3}\right)$.

The high temperature-high pressure (HTHP) filtration of the mud was conducted at $373-423 \mathrm{~K}$ and $3450 \mathrm{kPa}$, according to API procedures for HTHP fluid loss testing [18]. A filter area of $2258 \mathrm{~mm}^{2}$ was used and the filtrate volume was doubled to correct for standard filter area of $4581 \mathrm{~mm}^{2}$.

\section{Results and Discussion}

\subsection{Copolymer Structures and Functional Properties}

Chemical stability against chain scission was built into the polymer-FLR by increasing its backbone strength. This was achieved through the attachment of the pendent groups and sterically hindering groups to offer structural rigidity. Functional monomers were incorporated into the copolymers structures to impart salt resistance, thermal resistance and hydrolytic stability.

Acrylamide, hydroxyethyl methacrylate, $\mathrm{N}$-vinyl pyrrolidone and $N, N$-dimethyl acrylamide monomers constitute the structure of polymer-FLR. The backbone chain of a copolymer molecule is connected by $\mathrm{C}-\mathrm{C}$, which has the high thermal and salt stability. The dimethyl group and pyrrole ring jointly offer steric hindrance to the amide functionality and provide hydrolytic, salt and thermal stabilities in the structure. The vinyl pyrrolidone is relatively inert toward salt and acidic medium and the inelastic structure of its pyrrole ring improves the thermal stability of the polymer-FLR. The homopolymer of hydroxyethyl methacrylate is insoluble in water but the presence of hydrophilic pendent group will cause it to swell in the aqueous medium. It is capable of absorbing up to 
$600 \%$ water of its dry weight depending on the physical and chemical configuration of the polymer. This unique property of hydroxyethyl methacrylate enriches the water retention capacity of its copolymer and makes its effective as a drilling mud fluid loss reducer. The combined effect of the $\mathrm{CO}_{2}$ and pyrrole ring provides temperature and salt resistance in the polymer-FLR.

\subsection{FTIR and Proton N uclear Magnetic Resonance ( $\left({ }^{1} \mathrm{H}\right.$ N M R) Spectral Analyses}

The spectrum of polymer-FLR is presented in Fig. 1. The strong and broad absorption peak at $3405 \mathrm{~cm}^{-1}$ was assigned to the stretching vibration of $\mathrm{N}-\mathrm{H}$ as well as $-\mathrm{OH}$ stretching from both HEMA and hydrolyzed AM. The absorption peaks observed at $2939 \mathrm{~cm}^{-1}$ was ascribed to the stretching vibration of $-\mathrm{CH}_{3}$ and $-\mathrm{CH}_{2}$. The absorption peak of $1659 \mathrm{~cm}^{-1}$ was attributed to the stretching peak of $\mathrm{C}=\mathrm{O}$ whilst the peak at $1567 \mathrm{~cm}^{-1}$ was assigned to the stretching vibration of C-N. Peak at $1442 \mathrm{~cm}^{-1}$ reflected a characteristic absorption of NVP. However, a less pronounced peak at $1085 \mathrm{~cm}^{-1}$ signified the absorption of carboxylate esters of HEMA. Rocking of $\mathrm{C}-\mathrm{H}$ bond of the methyl group at $1291 \mathrm{~cm}^{-1}$ was assigned to HEMA and DMAM.

The ${ }^{1} \mathrm{H}$ NMR spectrum of the copolymer in Fig. 2 revealed shift at $1.0 \mathrm{ppm}$ which indicated a methyl proton on the backbone. Chemical shifts at 1.6, 1.8 and 2.1 represented the methylene $\left(-\mathrm{CH}_{2}\right)$ proton and methine $(-\mathrm{CH})$ in the backbone, and also $-\mathrm{CH}_{2}-\mathrm{CH}_{2}-\mathrm{N}-$ in the NVP ring. The chemical shift at $\delta=2.8 \mathrm{ppm}$ reflected $-\mathrm{CH}_{3}$ of $\mathrm{N}\left(\mathrm{CH}_{3}\right)_{2}$ in DMAM. The hydrogens of $-\mathrm{CH}_{2}-\mathrm{C}=\mathrm{O}$ in NVP ring and methylene group in $-\mathrm{CH}_{2}-\mathrm{OH}$ of HEMA, appeared at $\delta=3.2 \mathrm{ppm}$. Signal at $3.5 \mathrm{ppm}$ was assigned to protons of methine $(-\mathrm{CH})$ of the backbone chain attached to NVP ring and methoxy protons $\left(-\mathrm{OCH}_{2}-\right)$ of $\mathrm{HEMA}$ while the shift at $3.8 \mathrm{ppm}$ suggested the hydrogens of $-\mathrm{OH}$ in HEMA and hydrolysed AM. The signal at $4.7 \mathrm{ppm}$ represented the hydrogens of $-\mathrm{NH}_{2}$ group and the $\mathrm{D}_{2} \mathrm{O}$ solvent.

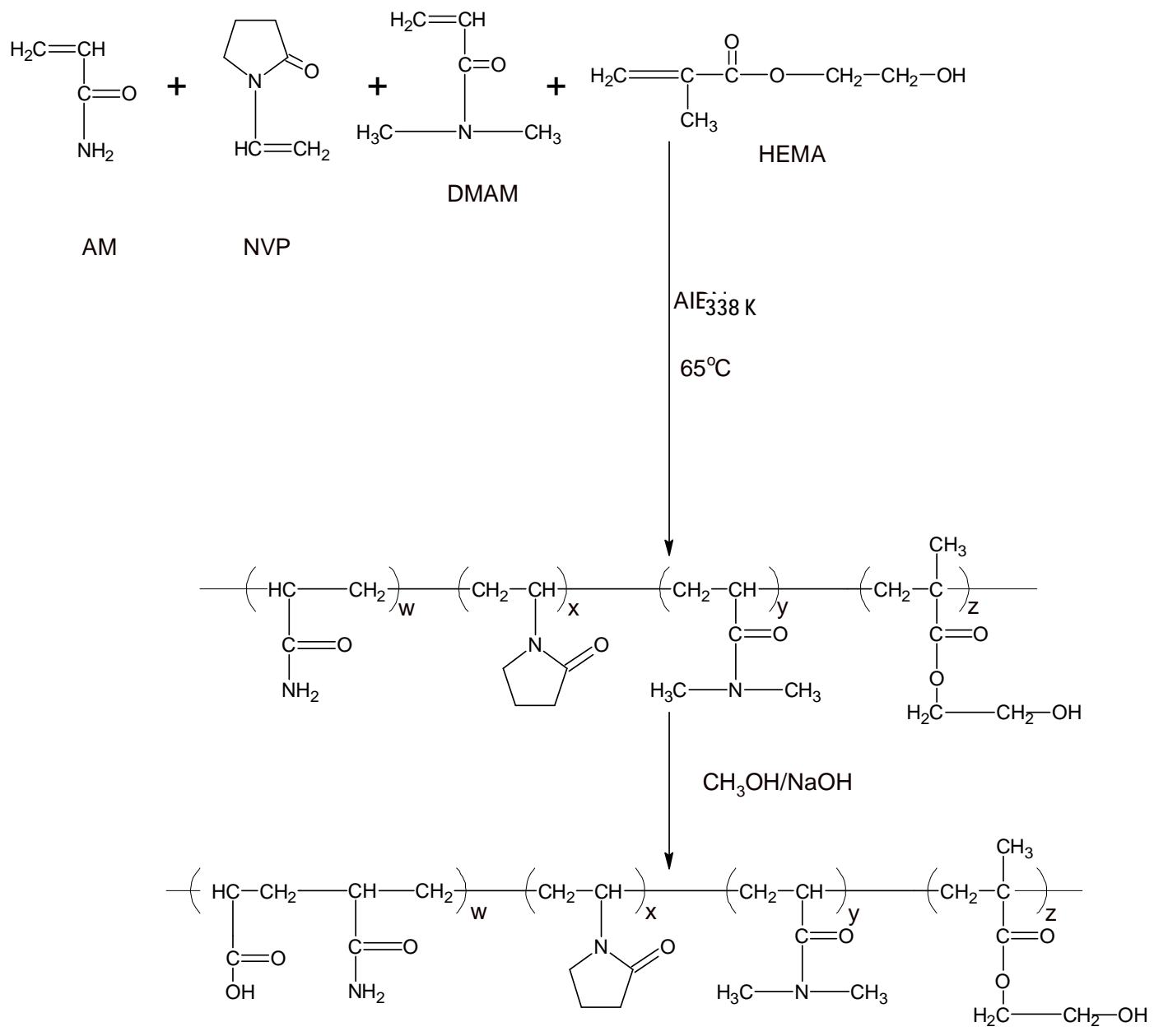

Scheme 1. Polymerisation reaction followed by partial hydrolysis to produce polymer-FLR 
Robert Nagre et al.

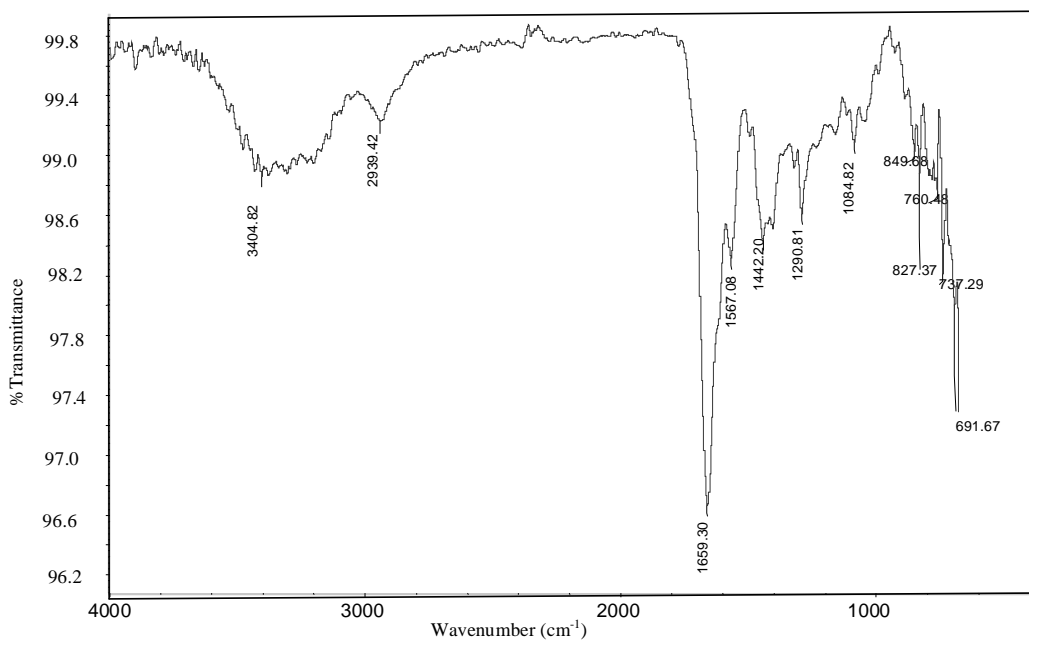

Fig. 1. FTIR spectrum of polymer-FLR

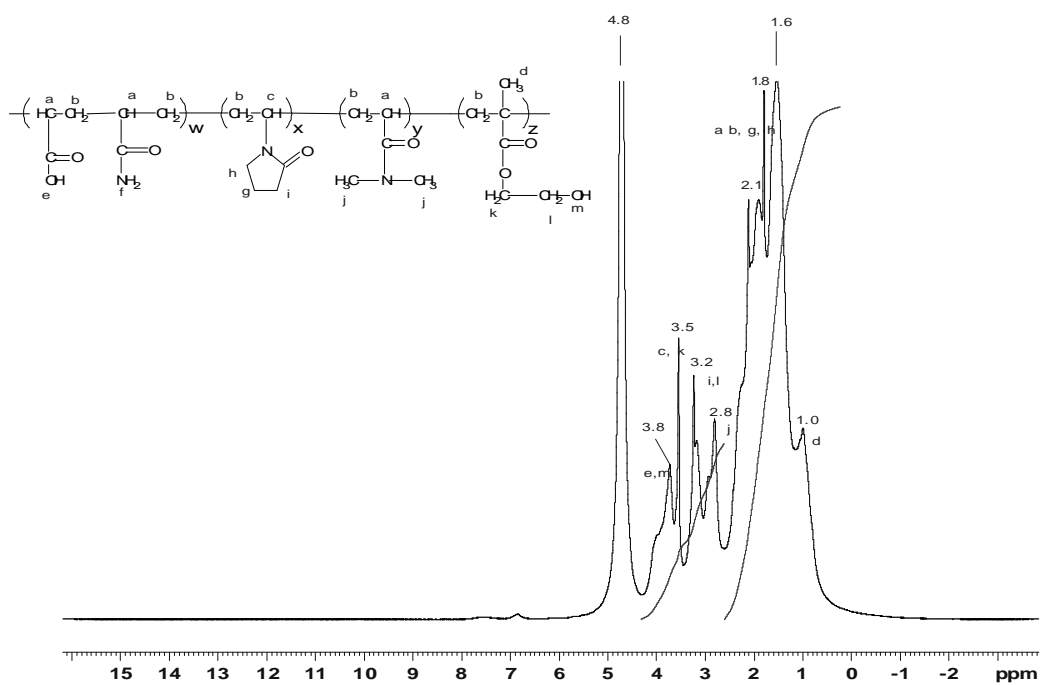

Fig. 2. ${ }^{1} \mathrm{H}$ NMR spectrum of polymer-FLR

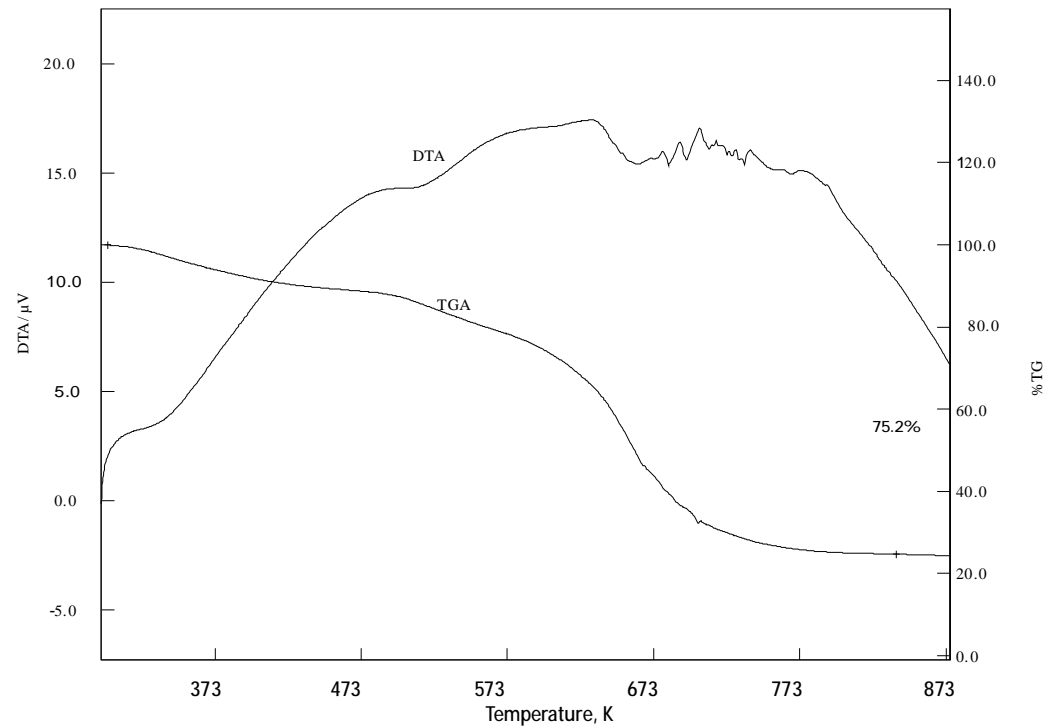

Fig. 3. Thermogravimetric and thermal differential curves of polymer-FLR 


\subsection{Thermogravimetric and Thermal Differential Analysis of Polymer-FLR}

Results of thermogravimetric and thermal differential analyses of polymer-FLR were interpreted in consistence with previous reports $[15,19]$.

The thermogravimetric and thermal differential analyses curves of polymer-FLR are shown in Fig. 3. The initial gradual change on TGA-curve up to $373 \mathrm{~K}$ could largely be due to the presence of moisture. Substantial changes occurred after $623 \mathrm{~K}$, indicating the thermal stability upper threshold of the polymer. Within temperature range from 623 to $673 \mathrm{~K}$, significant loss in mass occurred on the TGA curve, which corresponded to decomposition, which is showed up on DTA curve as an endotherm. The polymer incorporates functional groups such as $\mathrm{CO}_{2}, \mathrm{OH}$, and pyrrole ring and thus exhibited a broader temperature range of degradation. The percentage weight of polymer left undecomposed or char residue after analysis at $873 \mathrm{~K}$ was about $24.8 \%$. There was no indication of crystallinity of polymer-FLR from the thermograms revealing that it is amorphous with an irregular chain structure and belongs to the class of atactic, statistical or highly branched polymer category.

\subsection{Effect of Temperature and Salinity on Properties of Drilling Fluids}

\subsubsection{Rheological properties}

Results of thermal, salinity and pressure effect on properties of drilling mud are presented in Figs. 4-7. It is noteworthy to state that the rheological properties of saltcontaminated mud (with $5 \% \mathrm{NaCl}$ ) apparently increased following the addition of polymer-FLR compared to the blank. However, the apparent viscosities of the muds after heat treatment generally decreased with corresponding increase in temperature in the range of $393-423 \mathrm{~K}$. Comparatively, viscosity losses after heat treatment at $423 \mathrm{~K}$ with reference to values of unaged samples at $298 \mathrm{~K}$ were observed to be decreased by $52.0 \%$ (blank) and $39.4 \%$ (polymer-FLR). Plastic viscosity of the polymer-FLR also reduced slightly after hot-aging at $423 \mathrm{~K}$ compared to values of the unaged sample. The blank experienced the highest reduction of plastic viscosity by $57.1 \%$ while polymer-FLRmud retained its initial PV. These observations clearly reflected the effectiveness of polymer-FLR as a drilling mud additive for viscosity enhancement at elevated temperatures compared to the blank.

Bentonite clay constitutes the primary viscosifier and fluid loss control agent in the mud investigated in this work. Intrinsically, bentonite clay consists structurally of two $\mathrm{Si}-\mathrm{O}$ tetrahedral sheets sandwiching each $\mathrm{Al}-\mathrm{O}-\mathrm{OH}$ (or $\mathrm{Mg}-\mathrm{O}-\mathrm{OH}$ in limited amount) octahedral sheet. In aqueous suspension, with sodium or calcium holding a weak bond between the octahedral sheet and the tetrahedral sheet, substantial water is drawn into the interlayer space and causes bentonite swelling. The behaviour of bentonite water suspension is complex because of anisometric clay particles, which expose different crystal faces, on which an electrical double layer can develop, differing both in sign and magnitude of the total surface potential [20,21]. Hence, the viscosifying behaviour of the aqueous bentonite-based mud in the absence of the polymer is primarily attributed to both clay-clay particle and clay particle-water interactions.

The addition of the polymer-FLR to the bentonitebased fluid caused non-newtonian flow behavior. PolymerFLR functions in the aqueous drilling mud through three mechanisms. Firstly, polymer-water interactions whereby polymer-FLR, being an anionic polyelectrolyte, water soluble and structurally hydrophilic creates a sheath of closely associated water molecules around its molecules. Secondly, by intra polymer-polymer and inter polymerpolymer interactions which also occur through a tangling mechanism. The anionic groups repel each other possibly via double layer forces, which cause the polymer chain to adopt a more expanded, rigid-rod-like conformation, resulting in an increase in fluid viscosity. The third mechanism is through clay-polymer interactions, in which a polymer molecule can adsorb onto more than one clay particle and form aggregate with the clay particles. The polymer-FLR used in the formulation of the drilling mud is anionic and one end of its molecule could attach to the positive sites of the bentonite clay particle with the remaining end free to hydrate and/or attach to other clay particles, resulting in an increase in viscosity. Thus, the cumulative effect of the above-stated mechanisms is an increase in hydrodynamic volume and improvement of rheological properties of the muds. It is important to note that relatively high viscosity build-up efficiency of the polyelectrolyte (polymer-FLR) may influence the drill mud to offer sufficient resistance to reduce slip velocity of the cuttings and effectively suspend cuttings during drilling operations.

Although substantial retention of rheological properties was achieved using the polymer-FLR, the viscosity, and yield point, nonetheless, decreased progressively with an increasing temperature. This was attributable to changes resulting from both the bentonite and polymer-FLR. For bentonite suspensions at high temperatures there is a complex interplay of factors leading to the reduction of the degree of the counter ions hydration, changes in the electrical double-layer thickness, increased thermal energy of the clay micelles, thermal degradation of the solid, with consequent reduction of the viscosity of the suspending medium and increasing dispersion of associated clay micelles [22]. In terms of the polymeric additive, the changes in mud behaviour could be ascribed to thermal degradation of the polymer-FLR. Additionally, increase in intermolecular distances arising from high temperature tends to lower the resistance of the fluid to flow and, hence, decreases its viscosity, yield point, and gel strength. 


\subsubsection{Temperature, salinity and pressure effect on mud fluid loss}

Filtration is a significant phenomenon that occurs in the wellbore because of the hydrostatic pressure exerted by the drilling mud. Mud filtrate invasion of the formation accelerates ionic diffusion which causes severe problems resulting in wellbore instability and possible wellbore failure. Swelling pressure is strongly influenced by the ionic diffusion at clay sites. It has been estimated that if water penetrates a formation at millimeters a day, ions will diffuse over centimeters per day while pressure diffuses over decimeters in a day.

Fig. 7 displays the API fluid losses and HTHP fluid losses of salt-contaminated muds under different thermal aging conditions. For API filtration at $\sim 700 \mathrm{kPa}$, the blank suffered a drastic increase in fluid loss by $16.0 \mathrm{~cm}^{3}$ after dynamic heat treatment from 373 and $423 \mathrm{~K}$ whilst the polymer-FLR incorporated mud increased by only $1.0 \mathrm{~cm}^{3}$ over the same temperature change. For the high temperature-high pressure (HTHP) filtrations between 373 and $423 \mathrm{~K}$ and $3450 \mathrm{kPa}$, polymer-FLR demonstrated

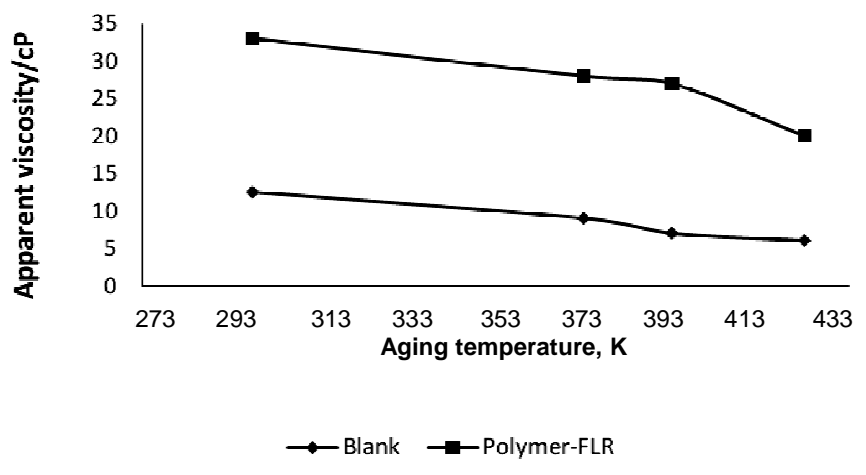

Fig. 4. Effect of polymer additive on apparent viscosity of salt contaminated mud at elevated temperatures

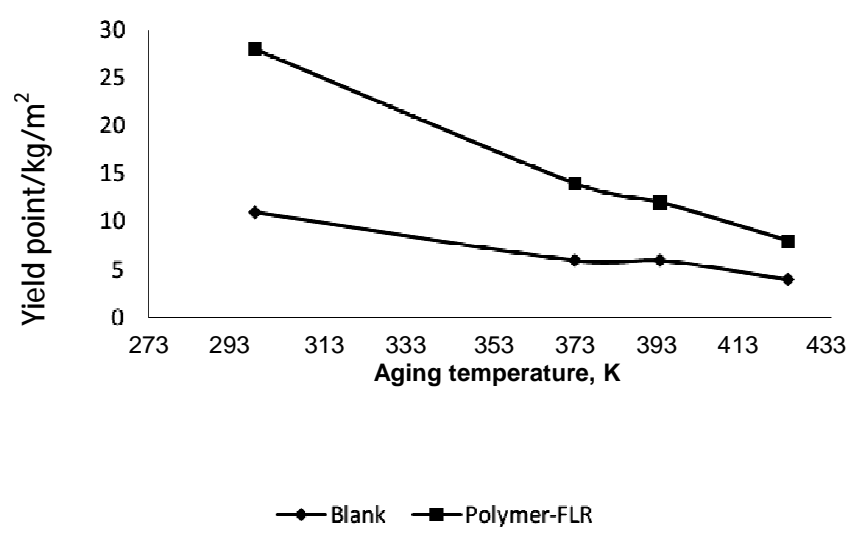

Fig. 6. Effect of polymer additive on yield point of salt contaminated mud at elevated temperatures significantly high fluid loss reduction by providing nearly 9-fold fluid loss reduction at $423 \mathrm{~K}$ than the blank.

Fluid loss reduction by polymers in drilling fluids has been known to occur by two mechanisms. Ionic polymers tend to adsorb on the oppositely charged edges of swollen clay particles through electrostatic interactions to form a thin layer of clay-polymer filter cake which reduces the movement of water across the cake. Polymers also increase the viscosity of fluid through a polymer-polymer interaction and polymer-water associations which ultimately reduces water mobility into the clay pores and lowers filtration rate. Thus the reduction in mud filtration loss through the incorporation of the polymer-FLR would maintain hole integrity, protect water sensitive shales and minimize formation damage.

The hydroxyethyl methacrylate component of the polymer-FLR is capable of absorbing up to $600 \%$ water of its dry weight depending on the physical and chemical configuration of the polymer. This unique property of the hydroxyethyl methacrylate combined with the ionic property of $-\mathrm{CO}_{2}-$ and hydrophilic pyrrolidone component in the polymer-FLR cumulatively impart the superior fluid loss control property of the polymer-FLR.

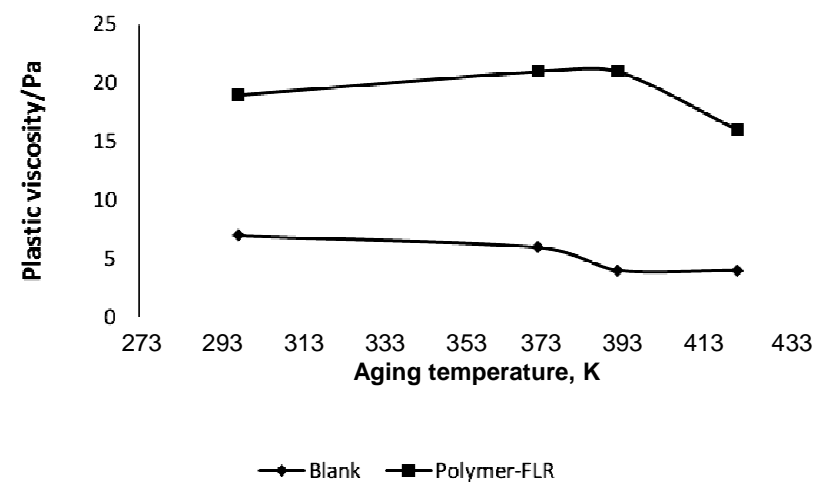

Fig. 5. Effect of polymer additive on plastic viscosity of salt-contaminated mud at elevated temperatures

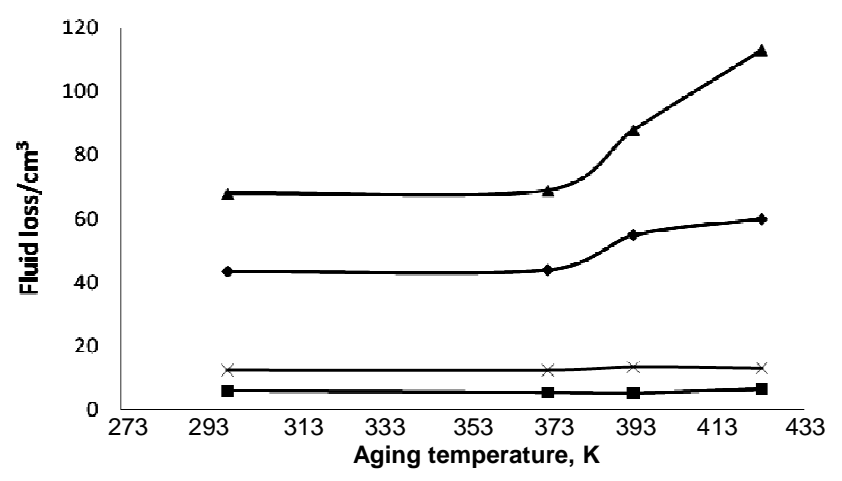

$\rightarrow$ Blank-API $\rightarrow$ Polymer-FLR-API $\longrightarrow$ Blank-HTHP $\longrightarrow$ Polymer-FLR-HTHF

Fig. 7. Effect of polymer-FLR additive on fluid loss of salted-mud at elevated temperatures 
The polymer-incorporated muds exhibited a relative thermal stability and salt tolerance compared to the blank. The uncontrolled fluid loss of the blank revealed a probable phase separation and more importantly structural breakdown of the bentonite clay. The polymer-FLR contains $-\mathrm{CO}_{2}$ and pyrrole ring which impart both thermal resistance and salt tolerance while the sulphonate group, besides, its strong water absorbing power, equally provides temperature and salt resistance in the polymer-incorporated muds.

\section{Conclusions}

Polymer-FLR was prepared by a solution polymerization using monomer feed AM/HEMA/NVP/ DMAM in the respective mole ratios of 46:20:26:8, total monomer concentration of $15.3 \mathrm{wt} / \mathrm{v} \%, \mathrm{pH}$ of 7.0 at 338 Kand 0.5 wt \% of 2-2'-azobisisobutyronitrile (AIBN) for a reaction time of $1.0 \mathrm{~h}$ and subsequently partially hydrolyzed at ambient temperature.

Polymer-FLR was relatively stable up to $573 \mathrm{~K}$ based on thermogravimetric and thermal differential analyses. Polymer-FLR was also very effective in salt contaminated water-based-bentonite clay mud by retaining adequate rheological profile and stability after heat treatment. Polymer-FLR maintained API fluid loss at $6.4 \mathrm{~cm}^{3}$, about 10-fold lower than that of the blank which suffered a drastic increase in a fluid loss $\left(60.0 \mathrm{~cm}^{3}\right)$ after dynamic heat treatment at $423 \mathrm{~K}$.

High temperature-high pressure (HTHP) filtrations performed at $423 \mathrm{~K}$ and $3447 \mathrm{kPa}$ using polymer-FLR achieved about 9-fold HTHP fluid loss reduction at $423 \mathrm{~K}$ in comparison with the blank. Hence, polymer-FLR can be used to control drill mud fluid loss at elevated temperatures and under moderate saline environment.

\section{Acknowledgements}

The authors thank Management of Kumasi Technical University, Ghana, Mrs Qingmei Zhao of College of Chemistry \& Environmental Engineering, Yangtze University and also the Director of Jingzhou Jiahua Technology Company, China for their support for the laboratory experiments.

\section{References}

[1] Ibeh C.: Master's Thesis. Texas A\&M University, College Station, Texas 2007.

[2] Amani M., Al-Jubouri M.: Energ. Sci. Technol., 2012, 4, 27. https://doi.org/10.3968/pdf

[3] Hassiba K., Amani M. Earth Sci. Res., 2013, 2, 175. https://doi.org/10.5539/esr.v2n1p175
[4] Nasiri A., Valizadeh M., Norouzi H., Hemmati M.: J. Petrol. Sci. Technol., 2012, 2, 37. https://doi.org/10.22078/jpst.2012.75

[5] Apugo-Nwosu T., Mohammed-Dabo I., Ahmed A. et al.: Brit. J. Appl. Sci. Technol., 2011, 1, 152.

https://doi.org/10.9734/BJAST/2011/407

[6] Nyland T., Azar J., Becker T., Lummus J.: SPE Drill. Eng., 1988, 3,195. SPE-14703-PA

[7] Blkoor S., Fattah K.: J. Petrol. Environ. Biotechnol., 2013, 4, 157. https://doi.org/10.4172/2157-7463.1000157

[8] Shah S., Asafa K.: SPE/ICoTA Coiled Tubing and Well

Intervention Conference and Exhibition, March 2014.

https://doi.org/10.2118/168289-MS

[9] Lai N., Qin X., Ye Z. et al.: J. Chem., 2013, 1.

https://doi.org/10.1155/2013/824785

[10] Karmakar G., Chakraborty C.: Indian J. Chem. Technol., 2006,

13, 162.

[11] Rashidi M.: PhD Thesis. University of Bergen, Norway 2010.

[12] Jousset F., Green D., Willhite G., McCool C.: SPE/DOE

Enhanced Oil Recovery Symposium, Tulsa, Oklakhoma 1990, 389.

https://doi.org/10.2118/20213-MS

[13] Lucas E., Mansur C., Spinelli L., Queirós Y. : Pure Appl. Chem., 2009, 81, 473. https://doi.org/10.1351/PAC-CON-08-07-21, IUPAC. [14] Perricone C., Enright D., Lucas J.: SPE Drill. Eng., 1986, 1, 358. https://doi.org/10.2118/13455-PA

[15] Nagre R., Zhao L., Frimpong I., Zhao Q-M.: Chem. Pap., 2016, 70, 206. https://doi.org/10.1515/chempap-2015-0184

[16] Quan H., Li H., Huang Z. et al.: Int. J. Polym. Sci., 2014. https://doi.org/10.1155/2014/201301

[17] Silverstein R., Webster F., Kiemle D.: Spectrometric

Identification of Organic Compounds. $7^{\text {th }}$ edn. Wiley, New York 2005.

[18] American Petroleum Institute. Recommended practice standard procedure for laboratory testing drilling fluid. API recommended practice $\left(8^{\text {th }}\right.$ edn). Washington 2008.

[19] Sharma R.: Adv. Appl. Sci. Res., 2012, 3, 3961.

www.pelagiaresearchlibrary.com.

[20] Singh P., Sharma V.: J. Sci. Ind. Res., 1997, 56, 281.

[21] Gungor N.: J. Appl. Polym. Sci., 2000, 75, 107.

https://doi.org/10.1002/(SICI)1097-4628(20000103)75:1<107::AIDAPP12>3.0.CO;2-P

[22] Alaskari M., Teymoori R.: IJE Transactions B, 2007, 20, 283.

http://www.ije.ir/Vol20/No3/B/8.pdf

Received: April 21, 2017 / Revised: June 20, 2017 /

Accepted: September 30, 2017

\section{ПОЛІМЕР-FLR ДЛЯ ЗНИЖЕННЯ ВТРАТ НАПОРУ БУРОВОГО РОЗЧИНУ}

\begin{abstract}
Анотація. 3 використанням акриламіду, гідроксиетилметакрилату, $N$-вінілпіролідону та N,N-диметил акриламіду внаслідок полімеризаиії вільних радикалів з наступним частковим гідролізом синтезовано полімер для зниження втрат напору рідини (полімер-FLR). Склад синтезованого полімеру підтверджено з використанням Фур' $\epsilon$ - та ${ }^{1}$ Н ЯМР-спектроскопії. Встановлено, ще втрати бурового розчину з використанням полімерFLR приблизно в 10 разів менші, ніж без нього, а зниження втрат при високому тиску і високій температурі - в 9 разів.
\end{abstract}

Ключові слова: синтез, полімер-FLR, розчин для буріння, втрата напору рідини, властивості бурового розчину. 